\title{
MOISTURE TRANSFER THROUGH MORTAR JOINTS: A SHARP-FRONT ANALYSIS
}

\author{
H. Janssen ${ }^{a, 1}$, H. Derluyn ${ }^{b, c}$, J. Carmeliet ${ }^{b, c}$
}

\author{
a: Building Physics Section, Department of Civil Engineering, K.U.Leuven, \\ Kasteelpark Arenberg 40, 3000 Leuven, Belgium \\ $b$ : Chair of Building Physics, ETH Zürich, Wolfgang-Pauli-Str. 15, 8093 Zürich, \\ Switzerland \\ c: Laboratory for Building Science and Technology, EMPA, Swiss Federal \\ Laboratories for Materials Science and Technology, Überlandstrasse 129, 8600 \\ Dübendorf, Switzerland \\ 1: corresponding author: hans.janssen@bwk.kuleuven.be, +32 32161326
}

\begin{abstract}
This article presents an experimental and analytical study of the hygric behaviour of mortar joints, with specific attention to the influences of the curing conditions. Capillary water uptake in masonry is visualized with the X-ray projection method and approximated with the sharp-front-theory. The results imply that the curing of the mortar between bricks modifies its hygric properties and introduces an interface resistance, with the effects proportional to the water extraction from the mortar during the curing.

The presented study uses the analytical sharp-front theory to analyse the X-rayvisualised moisture content profiles. Validation of the sharp-front findings with independently determined hygric properties and interface resistances confirms the reliability of the approach. The method's main advantage is its ease of application for interpretation of experiments, as the X-ray visualizations suffice as sole input data. The easy applicability is finally demonstrated on an independent measurement, which again corroborates the earlier findings.
\end{abstract}

\section{KEYWORDS}

moisture transfer, sharp-front theory, hygric properties, interface resistance, cement mortar 
Postprint: Janssen H, Derluyn H, Carmeliet J. 2012. Moisture transfer through mortar joints: a sharp-front analysis, Cement and Concrete Research, 42: 1105-1112.

doi:10.1016/j.cemconres.2012.05.004

\section{INTRODUCTION}

In large parts of the world, masonry is the prevalent solution for constructing building envelopes. Masonry is thus exposed to driving rain, night condensation, and occasionally to rising damp. The resulting wetting and drying of masonry may lead to damage: spalling caused by frost-thaw cycles, cracking due to hygric expansioncontraction, or visual deterioration because of salt efflorescences. All prevention and remediation of damage to masonry thus requires a thorough understanding of its hygric behaviour.

While its constituent materials - ceramic brick and cement mortar - are reasonably well understood, the hygric behaviour of masonry is often shown to deviate from the normal unsaturated flow theory. In this respect, most authors refer to an imperfect contact and hence an interface resistance in the brick-mortar bond plane [1-2]. The 'interface resistance' concept was introduced in [3], but in fact only for a non-bonded contact between building materials. Other authors refer to modified hygric properties for mortar cured in joints [4]. Both reasons are usually attributed to water extraction by the bricks from the fresh mortar [5-8]. This extraction may indeed modify the mortar's hygric properties, as it decreases the available curing water [9-12]. The extraction may similarly introduce interface resistances as it transports fine cement particles to the interface [7] and creates compaction pores near the interface [8]. While most authors [1-4] opt for 'introduced interface resistances' or 'modified hygric properties', [13] revealed that both influences simultaneously affect the moisture transfer in mortar joints. That study moreover demonstrated the relation between the modified hygric properties and introduced interface resistances and the water extraction during curing. This paper follows up on the analysis presented in [13], which mainly focused on identifying and explaining the effects of the curing conditions on the moisture transfer in mortar joints, by confronting X-ray visualisations and numerical simulations of capillary water uptake in masonry samples. This paper complements the earlier study in two ways. Most importantly it confirms [13]'s qualitative and quantitative findings by an alternative analysis of the original results as well as by an additional evaluation of an independent experiment from [4]. Furthermore, the analyses in this paper apply the analytical sharp-front method, being less laborious than [13]'s numerical simulations. The complete dataset compiled in [13] provides the ideal framework to assess the applicability and reliability of the sharp-front method for moisture transfer in masonry.

The paper is built up as follows. Section 2 presents the applied materials and methods, introducing the sample preparation, X-ray visualisation and sharp-front theory. The analysis of the results is presented in Section 3, in particular the sharpfront analysis of the capillary water uptake in masonry. A comparison with independently determined data in Section 4 confirms the reliability of the sharp-front method. Section 5 analyses a measurement from literature with the sharp-front method and conclusions are stated in Section 6.

\section{MATERIALS AND METHODS}

\subsection{Sample preparation}

Three types of curing conditions for the mortar are considered:

1. mould mortar: made by pouring fresh mortar in a mould, with ensuing curing in the moulds;

2. wet cured mortar: made by joining capillary-saturated ceramic bricks with fresh mortar, with ensuing curing between the bricks;

3. dry cured mortar: made by joining oven-dry ceramic bricks with fresh mortar, with ensuing curing between the bricks;

The mould mortar is considered as the reference, the wet and dry cured mortars represent limiting cases of academic interest. In practice, bricks may show initial moisture contents in between these limits. 
Postprint: Janssen H, Derluyn H, Carmeliet J. 2012. Moisture transfer through mortar joints: a sharp-front analysis, Cement and Concrete Research, 42: 1105-1112.

doi:10.1016/j.cemconres.2012.05.004

A standardised cement mortar is used, obtained by mixing six parts (by weight) of river sand, two parts of P42.5 Portland cement and one part tap water. The resulting watercement factor is 0.5 . Red ceramic bricks are cut horizontally into two halves, each having a thickness of roughly $30 \mathrm{~mm}$, and are capillary saturated or oven dried. Fresh mortar is applied onto the sawed surface, with an intended thickness of $1 \mathrm{~cm}$. The second half brick is positioned on top, and slightly pressed into the mortar. All samples are cured under a damp cloth for 24 hours and afterwards moved to a curing chamber at $80 \% \mathrm{RH}$ and $20{ }^{\circ} \mathrm{C}$. After 28 days of curing, the vertical edges (roughly $1 \mathrm{~cm}$ ) of the masonry units are cut away to avoid boundary disturbances. Wet and dry cured masonry samples are obtained by further sawing.

For the mould mortar masonry samples, fresh mortar is cast in moulds. After curing and edge removal, appropriately sized mould mortar 'joints' are obtained by further sawing. The mould mortar joints and brick facets are assembled with thin kaolin clay layers between the different materials, to ensure perfect hydraulic contact [1].

All samples are finally dried at $50{ }^{\circ} \mathrm{C}$ and $3 \% \mathrm{RH}$ : low temperature drying is preferred to avoid damage during drying and to avoid removing chemically bound water from the cementitious materials. Figure 1 shows photographs of the joined bricks and of a masonry sample, and illustrates the average dimensions of the masonry samples.

\subsection{X-ray visualisation}

Capillary water uptake in the masonry samples is visualised by means of the X-ray projection method [14]. Water contact is imposed at the bottom of the sample, with evaporation via the lateral faces prevented by a vapour tight foil. The experiments here focus on moisture transfer perpendicular to the mortar joint. The study uses a Philips HOMX 161 system and AEA Tomohawk software. The X-ray source is set at $85 \mathrm{keV}$ and $0.30 \mathrm{~mA}$. X-ray pictures are acquired with a 12 bit $1024 \times 1024$ pixel resolution CCD camera at 25 frames/s. To reduce noise an average of 256 frames is used. The spatial resolution is $90-100 \mu \mathrm{m}$, and the moisture content resolution $4-5 \mathrm{~kg} / \mathrm{m}^{3}$. All Xray images are taken at predefined time steps in each experiment. Subtracting the $X$ ray image of the initially dry sample results in an X-ray image of the absorbed moisture only.

As an example, Figure 2 shows X-ray images for the wet cured masonry sample after one, two, and three hours of water uptake. The moisture fronts in the mortar joint are reasonably uniform, indicating a primarily one-dimensional flow. These images are transformed into moisture content distributions by calibrating the average X-ray intensity in the wet brick to the brick's capillary moisture content of $130 \mathrm{~kg} / \mathrm{m}^{3}-$ an average value, obtained from independent capillary absorption tests. These distributions are finally converted to moisture content profiles by averaging over $10 \mathrm{~mm}$ wide slices. Figure 3 illustrates some selected moisture content profiles for the three mortars for a $10 \mathrm{~mm}$ slice in the centre of each masonry sample.

\subsection{Sharp-front analysis}

Sharp-front theory assumes that real smooth moisture fronts can be simplified to sharp separations between the wet and the dry material zone. With this simplification, it can be established that the moisture accumulation during capillary water uptake into a twolayered composite is proportional to the square root of time for the bottom layer 1 (Eq. 1), and to the square root of an 'adapted' time for the top layer 2 (Eq. 2) [15,16]:

$$
\begin{array}{cc}
m=A_{\text {cap }, 1} \cdot t^{0.5} & t \leq\left(L_{1} f_{1} / S_{1}\right)^{2} \\
m=A_{\text {cap }, 2} \cdot \tau^{0.5}+w_{\text {cap }, 1} L_{1}-w_{\text {cap }, 2} L_{E} & t>\left(L_{1} f_{1} / S_{1}\right)^{2} \\
L_{E}=L_{1} \frac{K_{2}}{K_{1}} \quad \tau=t+\left(\frac{w_{c a p, 2} L_{E}}{A_{\text {cap }, 2}}\right)^{2}-\left(\frac{w_{\text {cap }, 1} L_{1}}{A_{\text {cap }, 1}}\right)^{2}
\end{array}
$$


Postprint: Janssen H, Derluyn H, Carmeliet J. 2012. Moisture transfer through mortar joints: a sharp-front analysis, Cement and Concrete Research, 42: 1105-1112.

doi:10.1016/j.cemconres.2012.05.004

in which $\mathrm{m}\left[\mathrm{kg} / \mathrm{m}^{2}\right]$ is the absorbed moisture mass per unit surface area, $A_{\text {cap }}\left[\mathrm{kg} / \mathrm{m}^{2} \mathrm{~s}^{0.5}\right]$ the capillary absorption coefficient, $\mathrm{w}_{\text {cap }}\left[\mathrm{kg} / \mathrm{m}^{3}\right]$ the capillary moisture content, $\mathrm{t}[\mathrm{s}]$ and $\tau[s]$ the actual and a shifted time, $K$ [s] the front permeability, $L[m]$ the length and $L_{E}$ $[\mathrm{m}]$ is material 1's equivalent length i.e. the hydraulic resistance of layer 1 expressed as a length of layer 2 . It should be observed that the original equations $[15,16]$ are formulated in terms of the 'absorbed moisture volume i', 'sorptivity $S$ ' and 'porosity f': these have been replaced here with their analagons ' $m$ ', ' $A_{\text {cap }}$ ' and ' $w_{\text {cap }}$ ', quantities which are also widely accepted within building physics. Eq. 2 may also be represented as $[15,16]$ :

$$
I_{2}=\frac{A_{\text {cap }, 2}}{W_{\text {cap }, 2}} \cdot \tau^{1 / 2}-L_{E}
$$

in which $\mathrm{I}_{2}[\mathrm{~m}]$ is the distance between the front and the brick-mortar interface. Approximating the measured moisture content profiles with Eq. 3 then allows the joint mortar's capillary absorption coefficient and the equivalent length of the underlying brick facet to be obtained. To that aim the following procedure is applied:

1. brick and mortar capillary moisture contents: the capillary moisture contents of brick and mortar $\mathrm{w}_{\mathrm{cap}, 1}$ and $\mathrm{w}_{\mathrm{cap}, 2}$ are given by the averaged maximal moisture contents reached in the brick and mortar, taken directly from the moisture content profiles in Figure 3;

2. brick and mortar moisture front location: by taking the location of half the capillary moisture content as representative of the position of the "sharp" moisture front, the moisture content profiles of Figure 3 are translated into a relation between front location and time. The evolutions of these front locations with time are shown in Figure 4;

3. brick capillary absorption coefficient: multiplication of the moisture front location in the brick with its capillary moisture content results in the evolution of the total absorbed moisture mass per unit surface $m$ with time t. Least-squares approximation with Eq. 1 gives the brick capillary absorption coefficient $A_{\text {cap } 1 \text {; }}$;

4. mortar capillary absorption coefficient \& brick equivalent length: least-squares approximation of the evolution of the moisture front location in the mortar joint with time with Eq. 3 ultimately yields the mortar's capillary absorption coefficient $A_{c a p, 2}$ and the brick's equivalent length $L_{E}$;

Figure 4 shows the evolution of the moisture front in the three different mortar joints for a $10 \mathrm{~mm}$ slice at the centre of each masonry sample: the distance $\mathrm{I}_{2}$ between the interface and the moisture front is shown as a function of the time passed since the front passed the interface (Figure 4a), and as a function of the shifted time $\tau$ (Figure 4b). It needs to be noted that $\tau$ is not the same for the different mortars, as the length of the bottom brick and the hygric properties of the mortar are not the same. Approximations with Eq. 3 are additionally shown in Figure 4. The good agreement between measurements and approximations confirms that the sharp-front method satisfactorily describes capillary water uptake in masonry samples.

\section{ANALYSIS OF RESULTS}

\subsection{X-ray visualisation}

The capillary moisture content of the different mortars is derived from Figure 3: 130, 120 and $95 \mathrm{~kg} / \mathrm{m}^{3}$ for mould, wet cured and dry cured mortar respectively. Their values demonstrate the influence of the curing conditions. The capillary moisture contents are inversely related to the moisture extraction during curing: none for mould mortar, low for wet cured mortar and high for dry cured mortar. A first deviation in the hygric behaviour of mortar joints in comparison to mould mortar is thus caused by a modification of the hygric properties, specifically the capillary moisture content. Figure 5 shows the evolution of the moisture fronts in the mortar joint, where the 
Postprint: Janssen H, Derluyn H, Carmeliet J. 2012. Moisture transfer through mortar joints: a sharp-front analysis, Cement and Concrete Research, 42: 1105-1112.

doi:10.1016/j.cemconres.2012.05.004

distance between interface and moisture front is plotted as a function of the time elapsed since the front passed the interface. The front evolutions have been determined for 6 neighbouring $10 \mathrm{~mm}$ slices in each of the samples. While the mould mortar is fairly homogeneous, the heterogeneity of the wet cured and dry cured mortars becomes clear immediately. It can, despite the heterogeneity, be noted that the average front velocity in the mortar joints clearly also depends on the curing conditions. Thus, a direct relation with the water extraction during curing is again observed: the front velocity is high for mould mortar, intermediate for wet cured mortar and low for dry cured mortar.

This second deviation of the hygric behaviour of mortar joints can also be caused by modification of the hygric properties, specifically the capillary absorption coefficient, or by introduction of interface resistances. To differentiate between both options, further analysis with the sharp-front theory is necessary.

\subsection{Sharp-front analysis}

Sharp-front approximation is performed for the front evolutions shown in Figure 5. For the wet cured mortar, graphical results are collected in Figure 6 and numerical results are brought together in Table 1. While Figure 6 depicts a rather similar behaviour for all slices, the capillary absorption coefficients for mortar and the equivalent lengths of brick, given in Table 1, vary significantly. It can be noted though that high capillary absorption coefficients occur in combination with high equivalent lengths, and vice versa. The correlation between the two parameters implies that the inverse identification by the sharp-front approximation with Eq. 3 might be ill-conditioned: small variations in the measured front evolution may yield considerable changes in the resulting $A_{c a p}$ and $L_{E}$. This flaw is however easily resolved, by averaging over several slices from the same sample: when the average values for $A_{c a p}$ and $L_{E}$ from the 6 slices are inserted in Eq. 3, a fair description of the global behaviour of the wet cured mortar is obtained, as depicted in Figure 6. The mould mortar and dry cured mortar behave likewise: the averages from 6 slices are thus assumed representative. The resulting mortar capillary absorption coefficients and equivalent brick lengths for the three curing conditions are collected in Table 2. Minima and maxima reveal the original spread between the different slices.

\subsection{Properties and resistances}

Firstly, the results verify the influence of the water extraction during curing on the capillary absorption coefficient, as its value is inversely related to this water extraction. The larger equivalent lengths $L_{E}$ for the wet and the dry cured mortars, in comparison to the $L_{E}$ for the mould mortar, furthermore clearly point out that a resistance is present in the brick-mortar interface. The capillary absorption coefficient is defined as [15]-[16]:

$$
A_{\text {cap }}=\left(2 w_{\text {cap }} \mathrm{Kp}_{c, f}\right)^{0.5}
$$

where $p_{c, f}[\mathrm{~Pa}]$ is the wetting front capillary pressure, defined as the effective strength of the capillary forces that cause absorption in porous materials [17]. Bouwer [18] approximates it with the bubbling potential, the largest potential for which the material remains saturated. Moisture retention curves for the three mortars shown in [13] indicate largely similar pore structures, differing primarily by their magnitudes: $p_{c, f}$ is hence assumed to be the same for all three mortar types. Under that condition, $\mathrm{K}_{\text {mould }}$ $>\mathrm{K}_{\text {wet }}>\mathrm{K}_{\text {dry }}$ must hold, as the $\mathrm{A}_{\text {cap }}$ differences are larger than the $\mathrm{w}_{\text {cap }}{ }^{0.5}$ differences. Eq. 2b suggests $L_{E \text {,mould }}>L_{E \text {,wet }}>L_{E \text {,dry }}$ if no interface resistances are present. The experimentally noted $L_{E \text {,mould }}<L_{E \text {,wet }}<L_{E \text {,dry }}$ can solely be explained by the presence of a resistance in the brick-mortar interface. It can similarly be concluded that the interface resistance is larger for the dry cured mortar than for the wet cured mortar. The influences of the curing conditions on the front velocity hence involve a 
Postprint: Janssen H, Derluyn H, Carmeliet J. 2012. Moisture transfer through mortar joints: a sharp-front analysis, Cement and Concrete Research, 42: 1105-1112.

doi:10.1016/j.cemconres.2012.05.004

combination of modified hygric properties (particularly the capillary absorption coefficient) and introduced interface resistances.

If we assume that $L_{E \text {,mould }}$ does not incorporate any interface resistance [1] and thus only contains the material resistance of the brick facet, then the material and interface resistance can be distinguished in $L_{E \text {,wet }}$ and $L_{E, \text { dry }}$. For the wet cured mortar:

$$
\begin{aligned}
& L_{E, \text { wet }}=L_{E \text {,wet,MAT }}+L_{E \text {,wet,IF }} \\
& =\mathrm{L}_{\text {brick }} \cdot \mathrm{K}_{\text {wet }} / \mathrm{K}_{\text {brick }}+\mathrm{L}_{\mathrm{E} \text {,wet,IF }} \\
& =\mathrm{L}_{\text {brick }} \cdot \mathrm{K}_{\text {mould }} / \mathrm{K}_{\text {brick }} \cdot \mathrm{K}_{\text {wet }} / \mathrm{K}_{\text {mould }}+\mathrm{L}_{\mathrm{E} \text {,wet, IF }} \\
& =L_{E, \text { mould }} \cdot\left(A_{\text {cap,wet }}^{2} \mathrm{w}_{\text {cap,mould }}\right) /\left(A_{\text {cap,mould }}^{2} \mathrm{w}_{\text {cap,wet }}\right)+L_{E, \text { wet, IF }} \\
& L_{E \text {,wet,IF }}=L_{E \text {,wet }}-L_{E \text {,mould }} \cdot\left(A_{\text {cap,wet }}^{2} w_{\text {cap,mould }}\right) /\left(A_{\text {cap,mould }}^{2} w_{\text {cap,wet }}\right)
\end{aligned}
$$

For the wet cured mortar $L_{E, \text { wet,IF }}$ is $2.7 \mathrm{~mm}$, for the dry cured mortar $L_{E, \text { dry,IF }}$ is $4.1 \mathrm{~mm}$; a transformation to actual resistances is included below.

\section{DISCUSSION OF RESULTS}

\subsection{Influence of curing conditions}

The previous paragraphs have clearly demonstrated that the deviating hygric behaviour of mortar joints has two sources: the hygric properties $\left(A_{\text {cap }}, w_{c a p}\right)$ of the wet and dry cured mortars differ from those of the mould mortar, and a brick-mortar interface resistance is present for the wet and dry cured mortars. These results support the hypothesis that the combination of modified hygric properties and introduced interface resistances control the hygric behaviour of mortar joints, and that both are evidently related to the water extraction during curing:

1. the capillary moisture content and capillary absorption coefficient are high for mould mortar, intermediate for wet cured mortar, and low for dry cured mortar; they are hence inversely related to the water extraction during curing;

2. the interface resistance is insignificant for mould mortar, intermediate for wet cured mortar and high for dry cured mortar; it is hence directly related to the water extraction during curing;

The sharp-front analysis thus corroborates the qualitative findings of [13]. Below, the sharp-front results are quantitatively validated with independent data for the hygric properties and interface resistances. Following this, the physical explanation for the observed effects of the curing conditions, as put forward in [13], is concisely brought back for reasons of completeness.

\subsection{Validation of results}

The mortar joints' hygric properties and interface resistances resulting from sharp-front analysis are compared to independent measurements for validation purposes. The capillary absorption coefficient and capillary moisture content are compared to data from capillary absorption measurements on isolated mould, wet cured and dry cured mortar samples. For the interface resistances, the numerical results of [13] are applied as reference.

To obtain isolated wet cured and dry cured mortar samples, the bricks from the original masonry units are cut away, ensuring that the loss of mortar is minimal, leading to mortar joint samples with dimensions $80 \times 40 \times 10 \mathrm{~mm}^{3}$. To mimic the original capillary uptake in the masonry samples, the $80 \times 40 \mathrm{~mm}^{2}$ 'bottom' surface of these isolated samples should be put in contact with water, to have the moisture front travelling along the $10 \mathrm{~mm}$ height of the joint. Capillary absorption in samples with such a small height is however impractical. The isolated mortar samples are therefore put on their long side: the water contact is made with the $80 \times 10 \mathrm{~mm}^{2}$ side surface, with the water front travelling along the $40 \mathrm{~mm}$ height of the joint sample; anisotropy of the mortar is hence assumed to be small. 
Postprint: Janssen H, Derluyn H, Carmeliet J. 2012. Moisture transfer through mortar joints: a sharp-front analysis, Cement and Concrete Research, 42: 1105-1112.

doi:10.1016/j.cemconres.2012.05.004

Results are collected in Table 3: these values qualitatively confirm the findings from the sharp-front analysis. The capillary moisture contents and absorption coefficients obtained here are a little higher though than the sharp-front values. Firstly, impeded air outflow via the upper brick facet may reduce the sharp-front results. It should furthermore be noted that both the sharp-front and the independent results reveal a large spread in the data, which may partially explain the observed discrepancies. The interface resistances were determined in [13] via numerical simulations, which led to $1.210^{10}$ and $2.510^{10} \mathrm{~s} / \mathrm{m}$ for the wet cured and dry cured mortar respectively. These were obtained with capillary absorption coefficients 0.015 and $0.010 \mathrm{~kg} / \mathrm{m}^{2} \mathrm{~s}^{0.5}$. The sharp-front analysis yields $L_{E, \text { wet, IF }} 2.7 \mathrm{~mm}$ and $L_{E, \text { dry,IF }} 4.1 \mathrm{~mm}$ for the wet and dry cured mortar respectively. X-ray visualisation and Boltzmann transformation of capillary uptake in isolated mortar samples in [13] led to $3.110^{-13} \mathrm{~s}$ as capillary saturated permeability for the wet cured mortar and $2.010^{-13} \mathrm{~s}$ for the dry cured mortar. If the front permeability $\mathrm{K}_{\mathrm{f}}$ is assumed equal to this saturated permeability of the mortar, then these $L_{E, I F}$ 's translate to interface resistances $0.910^{10} \mathrm{~m} / \mathrm{s}$ for the wet cured mortar and $2.010^{10} \mathrm{~m} / \mathrm{s}$ for the dry cured mortar. These were acquired with the capillary absorption coefficients 0.014 and $0.009 \mathrm{~kg} / \mathrm{m}^{2} \mathrm{~s}^{0.5}$. In view of the differences in the capillary absorption coefficients, the agreement of the sharp-front and numerical results for the interface resistances is very satisfactory.

Conclusively, the alternative approach confirms, qualitatively and quantitatively, the reliability of the sharp-front hygric properties and interface resistances. This means that the sharp-front method can reliably be applied to interpret experimental results of moisture transfer in layered and bonded materials, with consideration of hygric property modification and interface resistance introduction. The sharp-front method requires no additional information on top of the original X-ray visualisation results, and is consequently more readily applicable for experiment interpretation than a numerical simulation approach, which requires extensive measurement of material properties. However, if any further analysis of moisture transfer in mortar joints under realistic boundary conditions is required, then the numerical approach is of course indispensable.

\subsection{Influence of water extraction}

The deviation of the hygric behaviour of mortar joints from that of mould mortar is hence reliably linked to a modification of the hygric properties and to an introduction of interface resistances. As already stated in the introduction, both are commonly attributed to the water extracted by the bricks from the fresh mortar during curing. Water extraction during curing was confirmed by execution of interrupted curing experiments in [13]. Mortar was applied on the brick face, and removed again after certain time intervals. The amount of water extracted from the mortar by the brick was obtained by weighing the brick before applying the mortar and after removal of the mortar. If expressed relative to the initial amount of water in the mortar when mixed, it was demonstrated that the dry cured mortar lost $30 \%$ and the wet cured mortar $6 \%$ over an interval of 90 minutes. This reduced the water/cement ratio's to 0.35 and 0.47 respectively. The latter value explains why even the wet cured mortar differs from the mould mortar.

This water extraction lessens the water/cement ratio in the mortar, decreasing its porosity and permeability [9-11]. Determination of the pore volume distributions [13] confirmed the reduced porosity for the wet cured and dry cured mortar. The reduction primarily affects the larger pores, explaining the related reduction in permeability. The water extraction furthermore transports fine particles to the interface - partially blocking brick pores at the interface - and causes compaction pores at the interface diminishing the capillary contact between brick and mortar $[7,8]$. Both lead to an interface resistance in the brick-mortar bond plane. Microscopy study [13] moreover showed the presence of compaction pores near the brick-mortar interface for the dry 
Postprint: Janssen H, Derluyn H, Carmeliet J. 2012. Moisture transfer through mortar joints: a sharp-front analysis, Cement and Concrete Research, 42: 1105-1112.

doi:10.1016/j.cemconres.2012.05.004

cured mortar, while for the wet cured mortar only air inclusions were found. More details can be found in [13].

\section{FURTHER APPLICATION}

The general applicability of the sharp-front method is illustrated by the analysis of the capillary water uptake experiment published by Brocken et al. [4]. In this analysis, capillary water uptake in a multi-layer masonry sample (first four layers: $46.5 \mathrm{~mm}$ ceramic brick, $13 \mathrm{~mm}$ cement mortar, $41 \mathrm{~mm}$ ceramic brick, $13 \mathrm{~mm}$ cement mortar) was visualised with a nuclear magnetic resonance technique. Use of oven-dry bricks for the masonry sample leads to a 'dry cured' mortar.

The moisture content profiles illustrated in Figure 7 indicate that the moisture front reaches the second interface ( $13 \mathrm{~mm}$ mortar - $41 \mathrm{~mm}$ brick) in less than two hours, and that it takes about four days to make it to the third interface $(41 \mathrm{~mm}$ brick $-13 \mathrm{~mm}$ mortar). In Brocken et al's simulation, on the other hand, the front passes that third interface in less than two hours. This discrepancy between the measurement and the simulation was attributed to modified hygric properties and/or introduced interface resistances, both of which were not considered in the simulation [4].

\subsection{Original measurement results}

The capillary moisture content and absorption coefficient of brick and mould mortar were measured independently: $270 \mathrm{~kg} / \mathrm{m}^{3}$ and $0.43 \mathrm{~kg} / \mathrm{m}^{2} \mathrm{~s}^{0.5}$ for brick, $190 \mathrm{~kg} / \mathrm{m}^{3}$ and $0.17 \mathrm{~kg} / \mathrm{m}^{2} \mathrm{~s}^{0.5}$ for mould mortar. The profiles shown in Figure 7 do however indicate that the capillary moisture content of the mortar joint is closer to $110 \mathrm{~kg} / \mathrm{m}^{3}$, a difference which is attributed to the curing conditions. Their large influence can be ascribed to the mortar's high water/cement ratio and the brick's high capillary absorption coefficient, both implying a large water extraction during curing. The large difference is moreover confirmed by moisture retention curves in [4]: they show that the employed 'MD' mortar is strongly affected by water extraction during curing. At -2 bar the mould mortar holds $170 \mathrm{~kg} / \mathrm{m}^{3}$, while the dry-cured mortar joint only holds $60 \mathrm{~kg} / \mathrm{m}^{3}$. The value of 110 $\mathrm{kg} / \mathrm{m}^{3}$ is thus accepted as the dry cured mortar's capillary moisture content, and is used in the analysis.

Brocken et al. [4] report that the 'first 20 profiles are measured continuously during the first two hours of absorption. According to the authors [19], the equipment was set-up such that the detector only measured until the end of each moisture content profile, after which it returned to the bottom of the sample to initiate the measurement of the next profile. This implies that the profiles shown in Figure 7 (top) are not spaced equally in time: the time spacing increases with the penetration depth of the profiles. Based on this principle, a representative time for each profile is deduced from Figure 7. For the first 4 profiles that represent the uptake in the brick, this leads to 1.3, 4.5, 8.7 and 13.6 minutes. At 13.6 minutes, the front has penetrated $46 \mathrm{~mm}$, up to the interface. This translates to a capillary absorption coefficient for the brick of 0.434 $\mathrm{kg} / \mathrm{m}^{2} \mathrm{~s}^{0.5}$, which agrees well with the independently obtained value $0.43 \mathrm{~kg} / \mathrm{m}^{2} \mathrm{~s}^{0.5}$, and thus confirms the validity of the time determination. After the first 4 profiles, the time spacing becomes more constant with intervals of 5 to 7 minutes between the profiles.

\subsection{Sharp-front approximation}

Sharp-front approximation of the moisture fronts 5 to 11 - at 18.9, 24.4, 30.6, 37.2, 43.8, 50.5 and 57.2 minutes, all located in the first mortar joint - gives a mortar joint capillary absorption coefficient of $0.067 \mathrm{~kg} / \mathrm{m}^{2} \mathrm{~s}^{0.5}$ and an equivalent length $L_{E}$ of $45.4 \mathrm{~mm}$. The approximation is illustrated in Figure 8, showing a fair agreement with the measurements. This example highlights the ease of application of the sharp-front method, as only a minimal amount of data is needed. The modification of the mortar's hygric properties $\left(A_{\text {cap }} 0.067 \mathrm{~kg} / \mathrm{m}^{2} \mathrm{~s}^{0.5}\right.$ instead of the original $\left.0.17 \mathrm{~kg} / \mathrm{m}^{2} \mathrm{~s}^{0.5}\right)$, and the introduction of a brick-mortar interface resistance $\left(L_{E} 45.4 \mathrm{~mm}\right.$, close to the actual brick 
Postprint: Janssen H, Derluyn H, Carmeliet J. 2012. Moisture transfer through mortar joints: a sharp-front analysis, Cement and Concrete Research, 42: 1105-1112.

doi:10.1016/j.cemconres.2012.05.004

facet length $46.5 \mathrm{~mm}$ ) confirm the earlier conclusions on the influence of the curing conditions. The steep reduction of the capillary absorption coefficient is again ascribed to the high water extraction during curing, as explained earlier for the capillary moisture content.

\subsection{Comparison of results}

The obtained hygric properties and equivalent lengths furthermore allow the estimation of the further progress of the capillary water uptake in the masonry. To that end however, the equivalent length is split into contributions from the brick material and the interface resistance. For the mould mortar masonry sample presented in the earlier analysis, the $30 \mathrm{~mm}$ brick facet was assumed to be the sole contribution to the $L_{E}$ of $0.3 \mathrm{~mm}$, implying that the ceramic brick to mould mortar permeability ratio $\mathrm{K}_{\text {brick }} / \mathrm{K}_{\text {mould }}$ is 100. The ratio of their capillary absorption coefficients on the other hand is close to 7 . This ratio similarly is close to 7 for the Brocken et al. ceramic brick and dry cured mortar. Their permeability ratio is therefore assumed to be of a similar size: $\mathrm{K}_{\text {brick }} / \mathrm{K}_{\text {dry }}$ is taken equal to 100 . This gives an $L_{E, m a t} 0.465 \mathrm{~mm}$ for the $46.5 \mathrm{~mm}$ brick facet and the equivalent length $L_{E, I F}$ for the interface resistance is $45 \mathrm{~mm}$.

The sharp-front theory allows the time for arriving at interface $\mathrm{j}$ in a multi-layered sample to be quantified as in [15]-[16]:

$$
\begin{aligned}
t_{j}=\sum_{i=1}^{j}\left(\frac{w_{\text {cap }, i} L_{i}}{A_{\text {cap }, i}}\right)^{2}\left(1+2 \frac{L_{E, i-1}}{L_{i}}\right) \\
L_{E, 0}=0 \\
L_{E, 1}=0.0454 m \\
L_{E, 2}=L_{1}+\frac{K_{1}}{K_{2}}\left(L_{2}+2 L_{E, I F}\right)=10.3 m
\end{aligned}
$$

where $t_{j}[s]$ is the time at which interface $j$ is reached, $L_{j}[m]$ are the lengths of the layers in the sample, $L_{E, I F}[m]$ is the equivalent length of the interface resistance, expressed as a length of mortar material, and $K_{i}[s]$ are the front permeabilities of the layers. $L_{E, I F}$ has been assumed to be valid for the two interface resistances, at the bottom and at the top of the mortar joint. The high value of $L_{E, 2}$ when compared to $L_{E, 1}$ has to be seen in light of the reference material: $L_{E, 2}$ is linked to the more permeable brick whereas $L_{E, 1}$ relates to the less permeable mortar.

Based on these values, the front would reach the second interface at 1.2 hours and the third interface at 94.2 hours, or almost four days. In the measurement shown in Figure 7 , the front arrives at the second interface after 1 to $1 \frac{1}{2}$ hour. After 4 days of water uptake, the second brick layer has reached capillary saturation, with minimal moisture penetration into the next mortar joint. While several assumptions have been made to facilitate the estimations, the final results agree very well with the experimental results from Brocken et al. [4], hence confirming the validity of the performed analysis.

\subsection{Properties and resistances}

Finally, the separate influences of the modified hygric properties and the introduced interface resistances are investigated, which requires an estimate for the $\mathrm{K}_{\text {brick }} / \mathrm{K}_{\text {mould }}$ ratio. Based on the capillary absorption coefficient definition in Eq. 4, and presuming that the wetting front capillary pressure $p_{c, f}$ is the same for the mould and the dry cured mortar, it can be shown that:

$$
\begin{aligned}
\mathrm{K}_{\text {brick }} / \mathrm{K}_{\text {mould }} & =\left(\mathrm{K}_{\text {brick }} / \mathrm{K}_{\text {dry }}\right)\left(\mathrm{K}_{\text {dry }} / \mathrm{K}_{\text {mould }}\right) \\
& =\left(\mathrm{K}_{\text {brick }} / \mathrm{K}_{\text {dry }}\right)\left(\mathrm{A}_{\text {cap,dry }}^{2} \mathrm{~W}_{\text {cap,mould }}\right) /\left(\mathrm{A}_{\text {cap,mould }}^{2} \mathrm{w}_{\text {cap,dry }}\right) \\
& =100 \cdot 0.268=27
\end{aligned}
$$


Postprint: Janssen H, Derluyn H, Carmeliet J. 2012. Moisture transfer through mortar joints: a sharp-front analysis, Cement and Concrete Research, 42: 1105-1112.

doi:10.1016/j.cemconres.2012.05.004

When neglecting the modification of hygric properties and the introduction of interface resistances, only 4.0 hours would be needed to arrive at the third interface. That is longer than predicted by the numerical simulation in [4], but of the same order of magnitude. When only accounting for modified hygric properties, the moisture front arrives at that third interface after 12.6 hours. When solely introduced interface resistances are considered, that arrival time becomes 86.2 hours. Hence, for the dry cured mortar considered here, the interface resistances have the strongest impact on the moisture transfer in the masonry. This however does not imply that correct estimation of the mortar joint's hygric properties is not necessary. If $L_{E}$ would be the sole fitting parameter in the sharp-front approximation (hence using hygric properties of the mould mortar), the time interval to arrive at the third interface decreases from 4 days to 2.2 days. This final remark implies that the method applied in [1]-[2], describing all deviations with just an interface resistance, cannot be assumed to be reliable: the introduction of interface resistances and the modification of hygric properties should be considered together.

\section{Conclusions}

Capillary water uptake experiments in masonry samples have been analysed to investigate the hygric behaviour of mortar joints, with a specific focus on the modification of hygric properties and the introduction of interface resistances due to water extraction during curing. Therefore three different mortars have been studied: a mould mortar, a wet cured mortar and a dry cured mortar. Capillary water uptake in masonry samples was visualised by means of the X-ray projection method and approximated with an analytical sharp-front-theory solution.

The visualised moisture content profiles indicated obvious differences between the different mortars: the height and velocity of the fronts are high for mould mortar, intermediate for wet cured mortar and low for dry cured mortar. The sharp-front analysis attributed those deviations to differing capillary moisture contents and capillary absorption coefficients for the mortars, and to differing brick-mortar interface resistances. These differences in hygric properties and interface resistances were in turn related to the water extraction during curing: none for the mould mortar, low for the wet cured mortar and high for the dry cured mortar. These sharp-front findings hence confirmed the outcomes of the original study in [13].

All interpretation of measurements in this paper made exclusive use of the sharp-front method, illustrating the minimal amount of additional data required, and the ease of fitting the analytical expressions to the measured results. The sharp-front solution does not allow the description of the actual 'smooth' moisture content profiles, nor does it permit the further quantification of moisture transfer under realistic boundary conditions. It has however been demonstrated that the theory gives a reliable approximation of the global moisture absorption during capillary water uptake in masonry samples. The consistency of the sharp-front results was corroborated by validating the hygric properties and interface resistances with independently obtained results. The article was concluded with an application of the sharp-front method to literature results, which corroborated all earlier findings.

\section{ACKNOWLEDGEMENTS}

The experimental work done by M.Sc. student Elke Deridder is highly appreciated. This research was partially sponsored by the Flemish Institute for Science and Technology, SBO project IWT03175 (Structural damage due to dynamic excitations: a multidisciplinary approach): their support is gratefully acknowledged. 
Postprint: Janssen H, Derluyn H, Carmeliet J. 2012. Moisture transfer through mortar joints: a sharp-front analysis, Cement and Concrete Research, 42: 1105-1112.

doi:10.1016/j.cemconres.2012.05.004

\section{REFERENCES}

[1]. A. Holm, M. Krus, H.M. Künzel, Feuchtetransport über Materialgrenzen im Mauerwerk, Restor. Build. Monum. 2 (1996) 375-396.

[2]. X. Qui, F. Haghighat, K. Kumaran, Moisture transport across interfaces between autoclaved aerated concrete and mortar, J. Therm. Envelope Build. Sci. 26 (2003) 213-236.

[3]. V.P. de Freitas, V. Abrantes, P. Crausse, Moisture migration in building walls Analysis of the interface phenomena, Build. Environ. 31 (1996) 99-108.

[4]. H.J.P. Brocken, O.C.G. Adan, L. Pel, Moisture transport properties of mortar and mortar joint: a NMR study, Heron 42 (1997) 55-69.

[5]. F.O. Anderegg, The effect of brick absorption characteristics upon mortar properties, Am. Soc. Test. Mater. P. 42 (1942) 821-836.

[6]. J.I. Davison, Loss of moisture from fresh mortar to bricks, Mater. Res. Standard. 1 (1961) 385-388.

[7]. C.J.W.P. Groot, Effects of water on mortar-brick bond, Heron 40 (1995) 57-70.

[8]. H.J.P. Brocken, M.E. Spiekman, L. Pel, K. Kopinga, J.A. Larbi, Water extraction out of mortar during brick laying: a NMR study, Mater. Struct. 31 (1998) 49-57.

[9]. S. Goto, D.M. Roy, The effect of W/C ratio and curing temperature on the permeability of hardened cement paste, Cement Concrete Res. 11 (1981) 575579.

[10]. B.K. Nyame, J.M. Illston, Relationships between permeability and pore structure of hardened cement paste, Mag. Concrete Res. 33 (1981) 139-146.

[11]. M.A. Sanjuán, R. Muñoz-Martialay, Influence of the water/cement ratio on the air permeability of concrete, J. Mater. Sci. 31 (1996) 2829-2832.

[12]. B. Johannesson, Transport and sorption phenomena in concrete and other porous media, $\mathrm{PhD}$ thesis, Division of Building Materials, Lund Institute of Technology, Lund University (2000).

[13]. H. Derluyn, H. Janssen, J. Carmeliet, Influence of the nature of interfaces on the capillary transport in layered materials, Constr. Build. Mater. 25 (2011) 36853693.

[14]. S. Roels, J. Carmeliet, Analysis of moisture flow in porous materials using microfocus X-ray radiography, Int. J. Heat Mass Transfer 49 (2006) 4762-4772.

[15]. C. Hall, W.D. Hoff, Water transport in brick, stone and concrete. Spon Press, New York, 2002.

[16]. M.A. Wilson, W.D. Hoff, C. Hall, Water movement in porous building materials XIII. Absorption into a two-layer composite, Build. Environ. 30 (1995) 209-219.

[17]. I. loannou, C. Hall, M.A. Wilson, W.D. Hoff, M.A. Carter MA, Direct measurement of the wetting front capillary pressure in a clay brick ceramic, J. Phys. D Appl. Phys. 36 (2003) 3176-3182.

[18]. H. Bouwer, Rapid field measurement of air entry value and hydraulic conductivity of soil as significant parameters of flow system analysis, Water Resour. Res. 2 (1966) 729-738.

[19]. L. Pel, Personal communication, 2009. 
Postprint: Janssen H, Derluyn H, Carmeliet J. 2012. Moisture transfer through mortar joints: a sharp-front analysis, Cement and Concrete Research, 42: 1105-1112.

doi:10.1016/j.cemconres.2012.05.004

\section{List of tables:}

1. Overview of $A_{\text {cap }}$ and $L_{E}$ resulting from approximation of the measured front evolutions with Eq. 3, for 6 neighboring slices of the wet cured mortar sample.

2. Overview of results from the sharp-front analysis.

3. Overview of results from the capillary absorption measurements.

\section{Table 1}

\begin{tabular}{l|cccccc} 
slice & 1 & 2 & 3 & 4 & 5 & 6 \\
\hline $\mathrm{A}_{\text {cap }}\left[\mathrm{kg} / \mathrm{m}^{2} \mathrm{~s}^{0.5}\right]$ & 0.0174 & 0.0111 & 0.0108 & 0.0135 & 0.0166 & 0.0169 \\
$\mathrm{~L}_{E}[\mathrm{~mm}]$ & 5.1 & 1.3 & 0.58 & 2.2 & 3.5 & 5.0
\end{tabular}

\section{Table 2}

\begin{tabular}{l|ccc} 
mortar type & mould & wet cured & dry cured \\
\hline capillary moisture content $\left[\mathrm{kg} / \mathrm{m}^{3}\right]$ & 130 & 120 & 95 \\
capillary absorption coefficient $\left[\mathrm{kg} / \mathrm{m}^{2} \mathrm{~s}^{0.5}\right]$ & 0.016 & 0.014 & 0.0088 \\
minimum-maximum & $0.016-0.016$ & $0.011-0.017$ & $0.007-0.011$ \\
equivalent length (brick \& interface) $[\mathrm{mm}]$ & 0.30 & 3.0 & 4.2 \\
minimum-maximum & $0.25-0.37$ & $0.58-5.1$ & $1.4-9.4$ \\
equivalent length (solely interface) $[\mathrm{mm}]$ & - & 2.7 & 4.1 \\
minimum-maximum & - & $0.58-5.1$ & $1.4-9.4$ \\
brick-mortar interface resistance $[\mathrm{s} / \mathrm{m}]$ & - & $0.910^{10}$ & $2.010^{10}$ \\
minimum-maximum & - & $0.15-1.510^{10}$ & $0.63-4.610^{10}$ \\
\hline
\end{tabular}

\section{Table 3}

\begin{tabular}{l|ccc} 
mortar type & mould & wet cured & dry cured \\
\hline capillary moisture content $\left[\mathrm{kg} / \mathrm{m}^{3}\right]$ & 147 & 134 & 97 \\
minimum-maximum & $138-158$ & $130-137$ & $92-103$ \\
capillary absorption coefficient $\left[\mathrm{kg} / \mathrm{m}^{2} \mathrm{~s}^{0.5}\right]$ & 0.019 & 0.015 & 0.0098 \\
minimum-maximum & $0.018-0.021$ & $0.013-0.017$ & $0.007-0.013$ \\
\hline
\end{tabular}


Postprint: Janssen H, Derluyn H, Carmeliet J. 2012. Moisture transfer through mortar joints: a sharp-front analysis, Cement and Concrete Research, 42: 1105-1112.

doi:10.1016/j.cemconres.2012.05.004

\section{List of figures:}

1. Illustrations of the joined bricks (left), masonry sample (centre) and average dimensions of the masonry sample (right).

2. X-ray visualised moisture saturation after 1, 2, 3 hour of capillary water uptake by wet cured mortar sample.

3. Overview of selected moisture content profiles for the mould mortar (top), wet cured mortar (centre) and dry cured mortar (bottom) samples. The first profile shown is at 14 minutes, the last at 2.5 hours. Profiles are taken from $10 \mathrm{~mm}$ slices in the centre of each sample. The grey lines indicate the location of the brick-mortar interface.

4. Measured and approximated evolutions of the distance between moisture front and the brick-mortar interface, as a function of the time elapsed since passing the interface (left) and as a function of the shifted time $\tau$ (right). Profiles are taken from $10 \mathrm{~mm}$ slices in the centre of each sample.

5. Measured evolutions of the distance between the moisture front and the brickmortar interface, as a function of the time elapsed since passing the interface. Profiles are taken from 6 neighbouring $10 \mathrm{~mm}$ slices in each sample.

6. Measured and approximated evolutions of the distance between the moisture front and the brick-mortar interface, as a function of the time elapsed since passing the interface, for the wet cured mortar sample. Profiles are taken from 6 neighbouring $10 \mathrm{~mm}$ slices in the sample.

7. Moisture content profiles measured during the water absorption in a brick masonry segment of ceramic brick and mortar joint. The first 20 profiles were measured continuously during the first two hours (a) while the next profiles were measured at time intervals of 2 hours ('Mo' refers to the mortar joint) (reproduced from [4]).

8. Measured and approximated evolution of the distance between the moisture front and the first brick-mortar interface, as a function of the time elapsed since passing the interface (left) and as a function of the shifted time $\tau$ (right) for the Brocken et al. sample. 
Postprint: Janssen H, Derluyn H, Carmeliet J. 2012. Moisture transfer through mortar joints: a sharp-front analysis, Cement and Concrete Research, 42: 1105-1112.

doi:10.1016/j.cemconres.2012.05.004
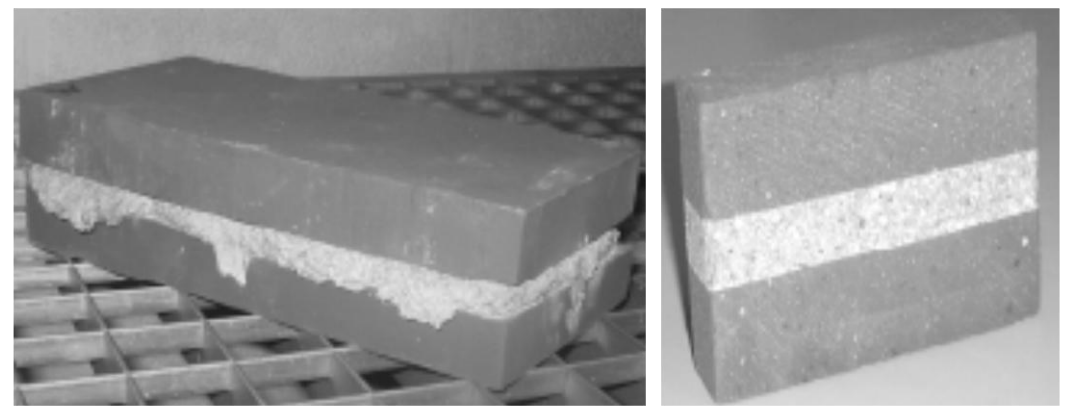

\begin{tabular}{|ll|}
\hline brick & $30 \mathrm{~mm}$ \\
\hline mortar & $10 \mathrm{~mm}$ \\
\hline brick & $30 \mathrm{~mm}$ \\
width: & $70 \mathrm{~mm}$ \\
\hline thickness: & $15 \mathrm{~mm}$
\end{tabular}

Figure 1

Illustrations of the joined bricks (left), masonry sample (centre) and average dimensions of the masonry sample (right). 
Postprint: Janssen H, Derluyn H, Carmeliet J. 2012. Moisture transfer through mortar joints: a sharp-front analysis, Cement and Concrete Research, 42: 1105-1112.

doi:10.1016/j.cemconres.2012.05.004
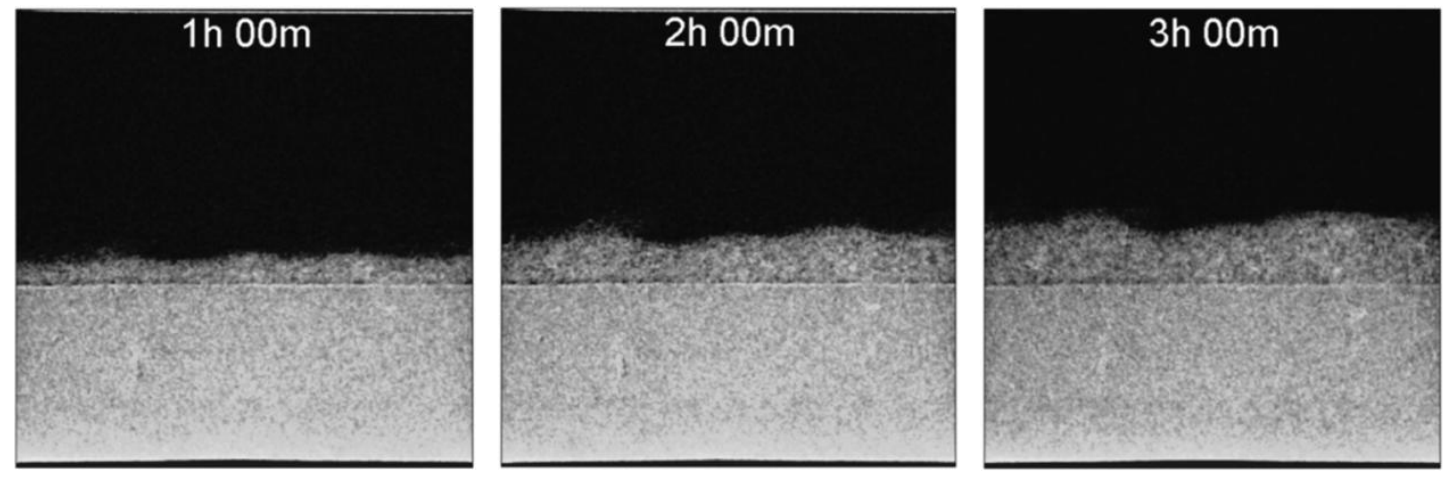

Figure 2

X-ray visualised moisture saturation after 1, 2, 3 hour of capillary water uptake by wet cured mortar sample. 
Postprint: Janssen H, Derluyn H, Carmeliet J. 2012. Moisture transfer through mortar joints: a sharp-front analysis, Cement and Concrete Research, 42: 1105-1112.
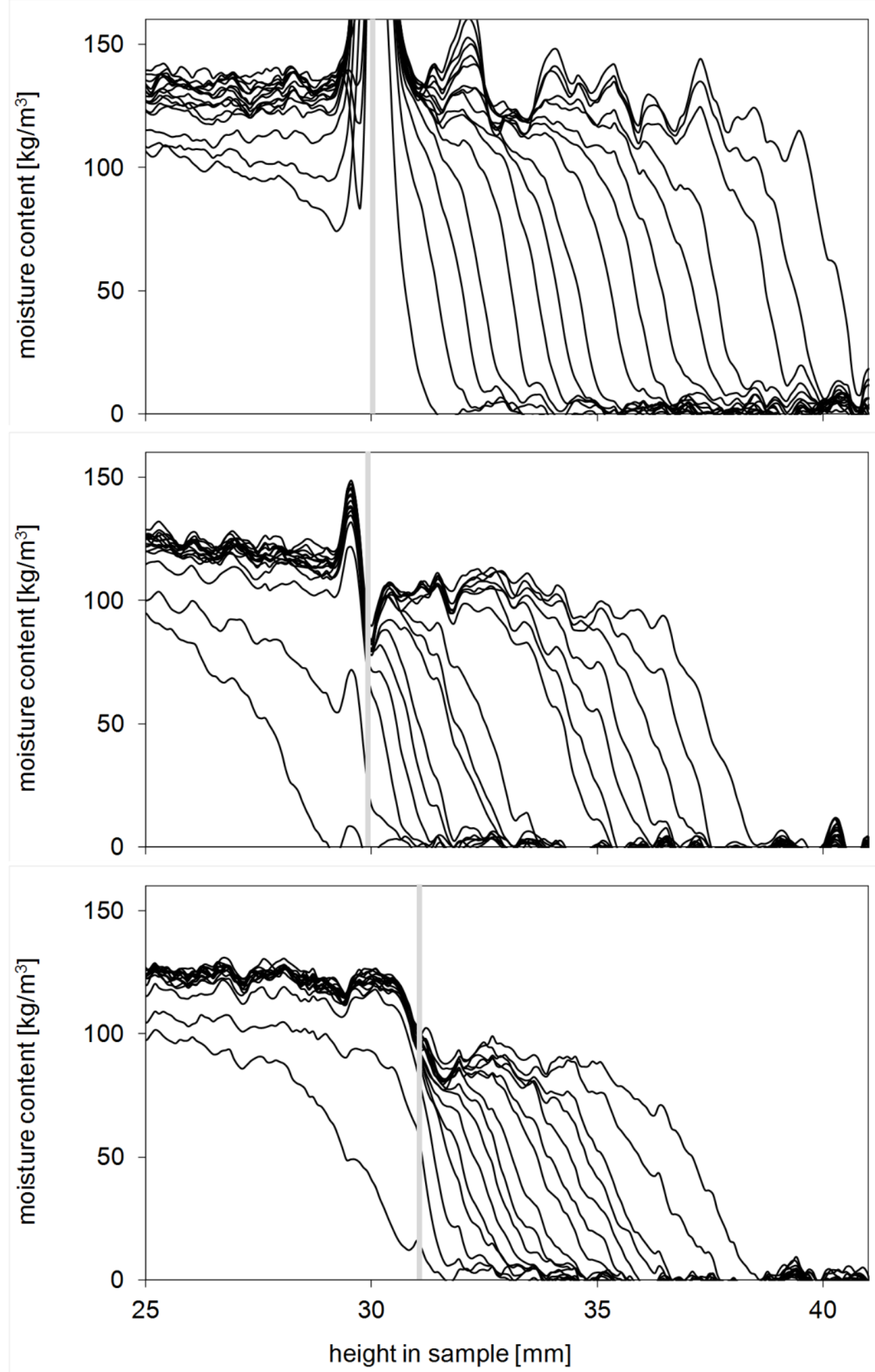

Figure 3

Overview of selected moisture content profiles for the mould mortar (top), wet cured mortar (centre) and dry cured mortar (bottom) samples. The first profile shown is at 14 minutes, the last at 2.5 hours. Profiles are taken from $10 \mathrm{~mm}$ slices in the centre of each sample. The grey lines indicate the location of the brick-mortar interface. 
Postprint: Janssen H, Derluyn H, Carmeliet J. 2012. Moisture transfer through mortar joints: a sharp-front analysis, Cement and Concrete Research, 42: 1105-1112.
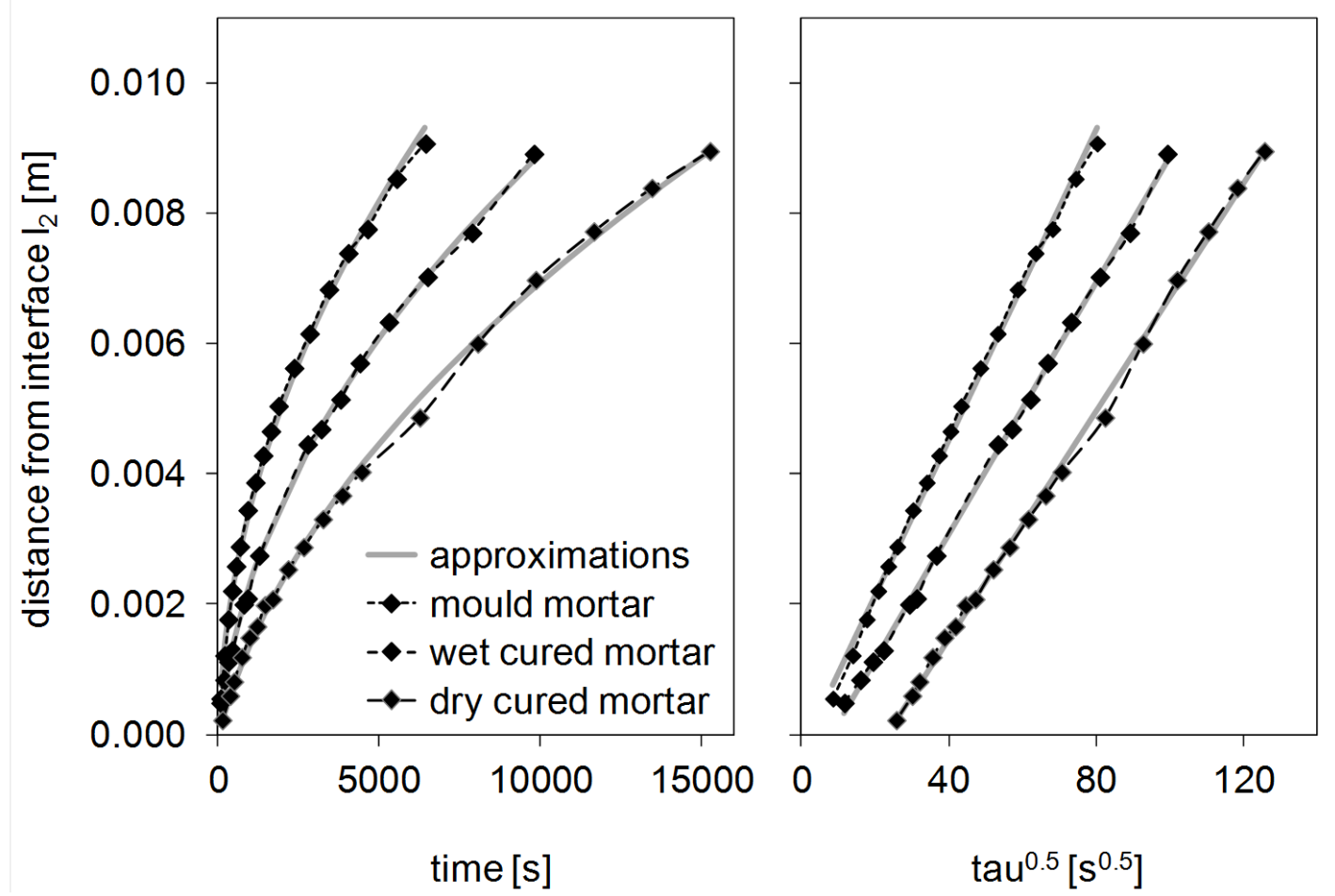

Figure 4

Measured and approximated evolutions of the distance between moisture front and the brick-mortar interface, as a function of the time elapsed since passing the interface (left) and as a function of the shifted time $\tau$ (right). The profiles are taken from $10 \mathrm{~mm}$ slices in the centre of each sample. 
Postprint: Janssen H, Derluyn H, Carmeliet J. 2012. Moisture transfer through mortar joints: a sharp-front analysis, Cement and Concrete Research, 42: 1105-1112.

doi:10.1016/j.cemconres.2012.05.004

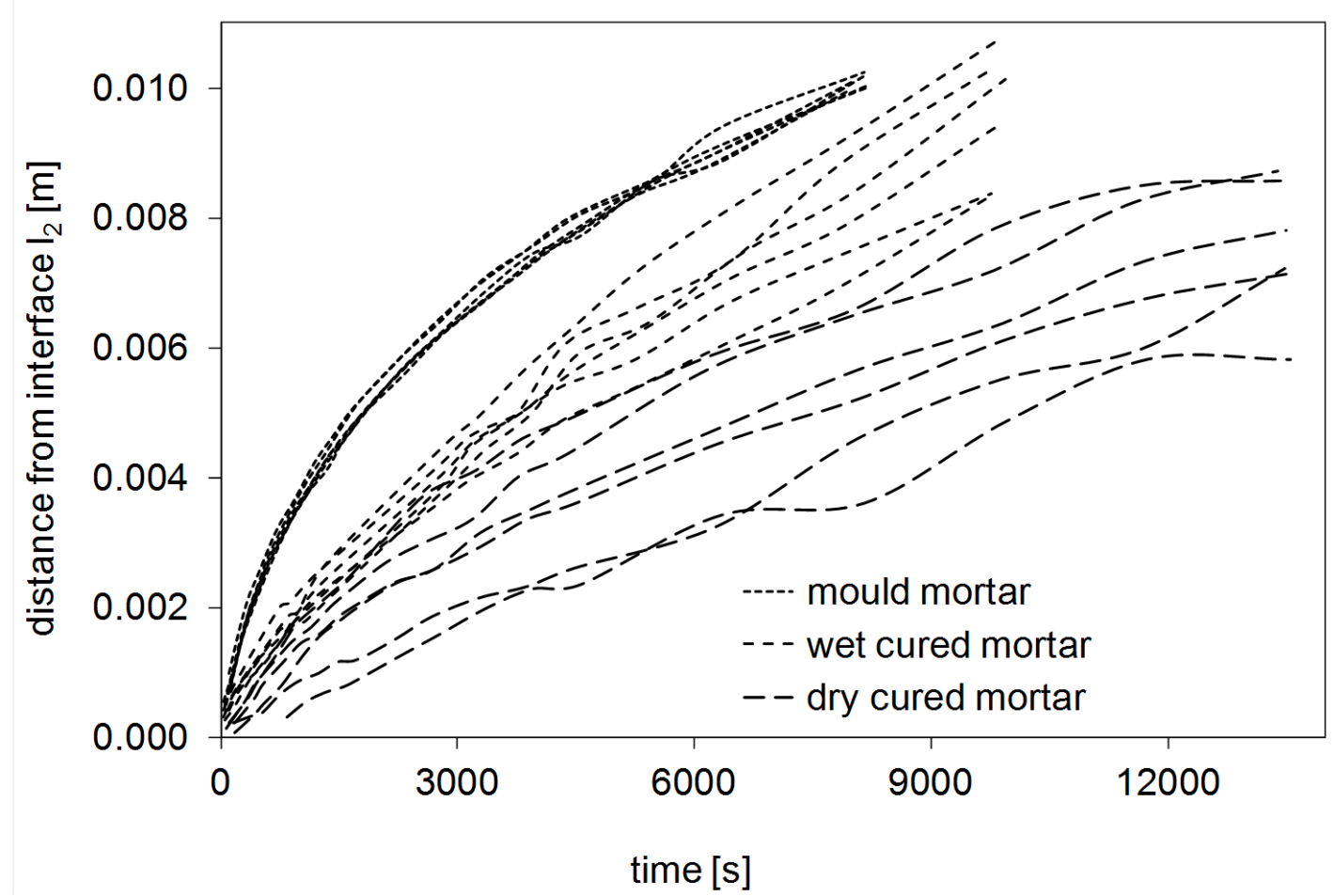

Figure 5

Measured evolutions of the distance between the moisture front and the brickmortar interface, as a function of the time elapsed since passing the interface. The profiles are taken from 6 neighbouring $10 \mathrm{~mm}$ slices in each sample. 
Postprint: Janssen H, Derluyn H, Carmeliet J. 2012. Moisture transfer through mortar joints: a sharp-front analysis, Cement and Concrete Research, 42: 1105-1112.

doi:10.1016/j.cemconres.2012.05.004

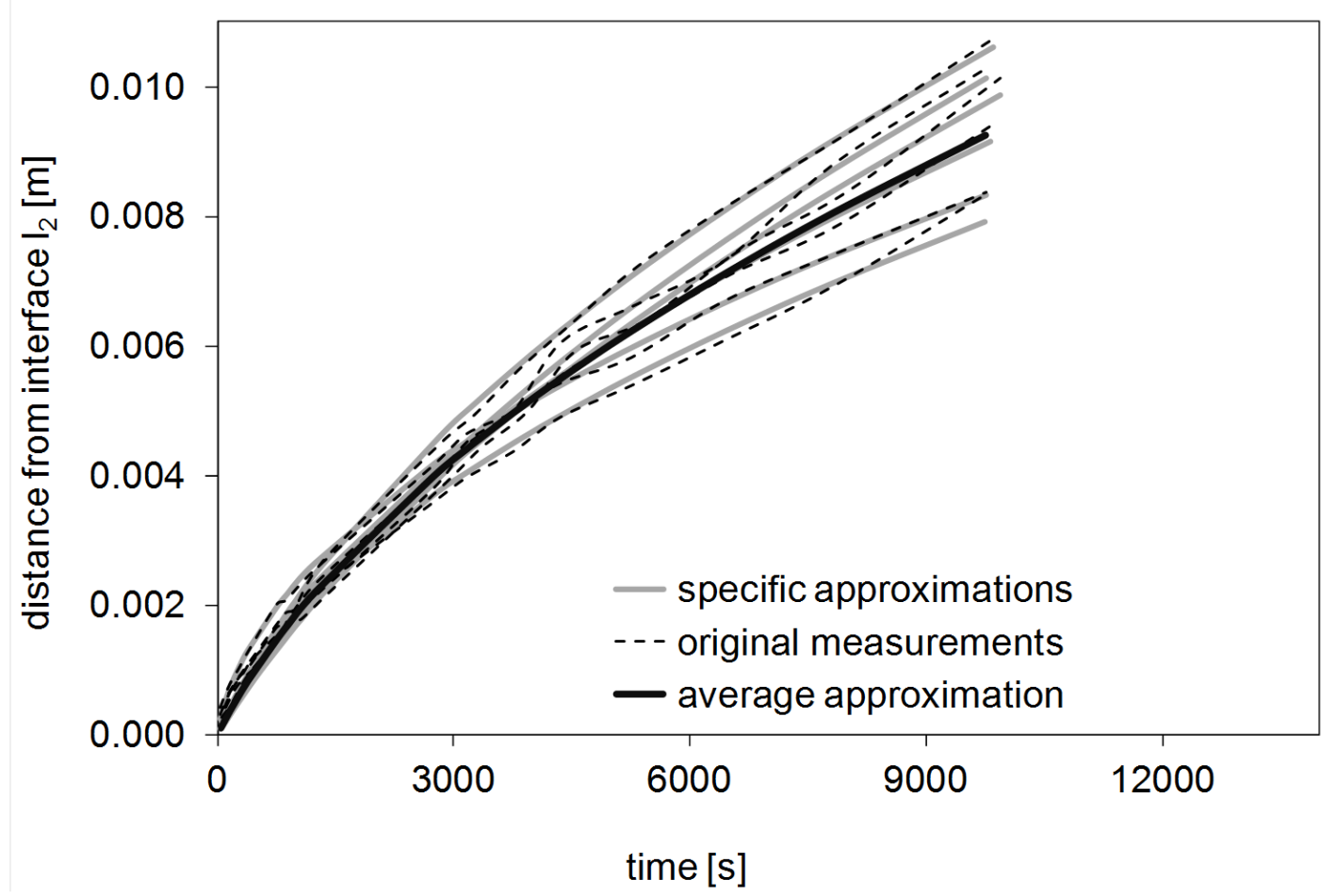

Figure 6

Measured and approximated evolutions of the distance between the moisture front and the brick-mortar interface, as a function of the time elapsed since passing the interface, for the wet cured mortar sample. Profiles are taken from 6 neighbouring $10 \mathrm{~mm}$ slices in the sample. 
Postprint: Janssen H, Derluyn H, Carmeliet J. 2012. Moisture transfer through mortar joints: a sharp-front analysis, Cement and Concrete Research, 42: 1105-1112.

doi:10.1016/j.cemconres.2012.05.004

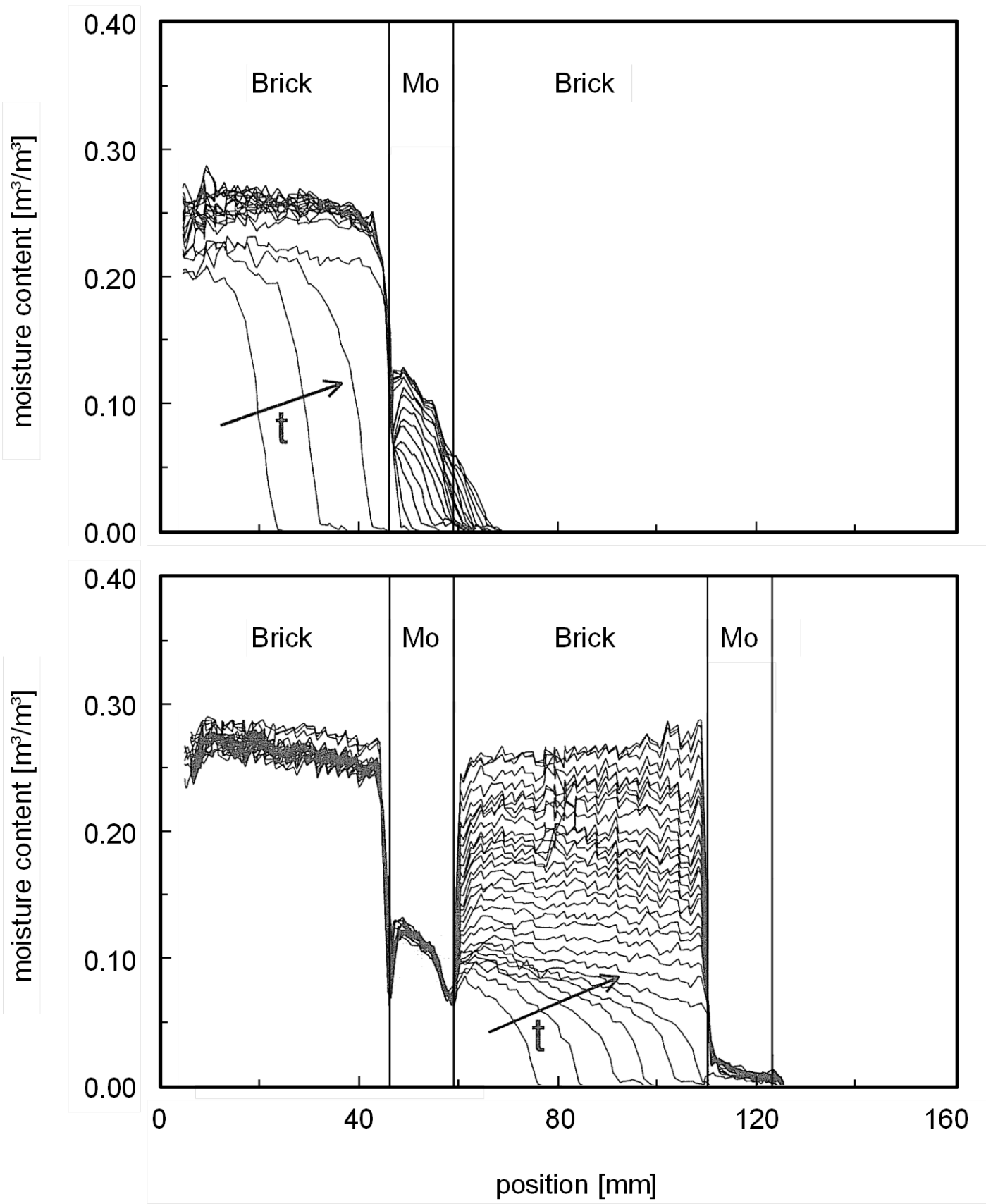

Figure 7

Moisture content profiles measured during the water absorption in a brick masonry segment of ceramic brick and mortar joint. The first 20 profiles were measured continuously during the first two hours (a) while the next profiles were measured at time intervals of 2 hours ('Mo' refers to the mortar joint) (reproduced from [4]). 
Postprint: Janssen H, Derluyn H, Carmeliet J. 2012. Moisture transfer through mortar joints: a sharp-front analysis, Cement and Concrete Research, 42: 1105-1112.

doi:10.1016/j.cemconres.2012.05.004
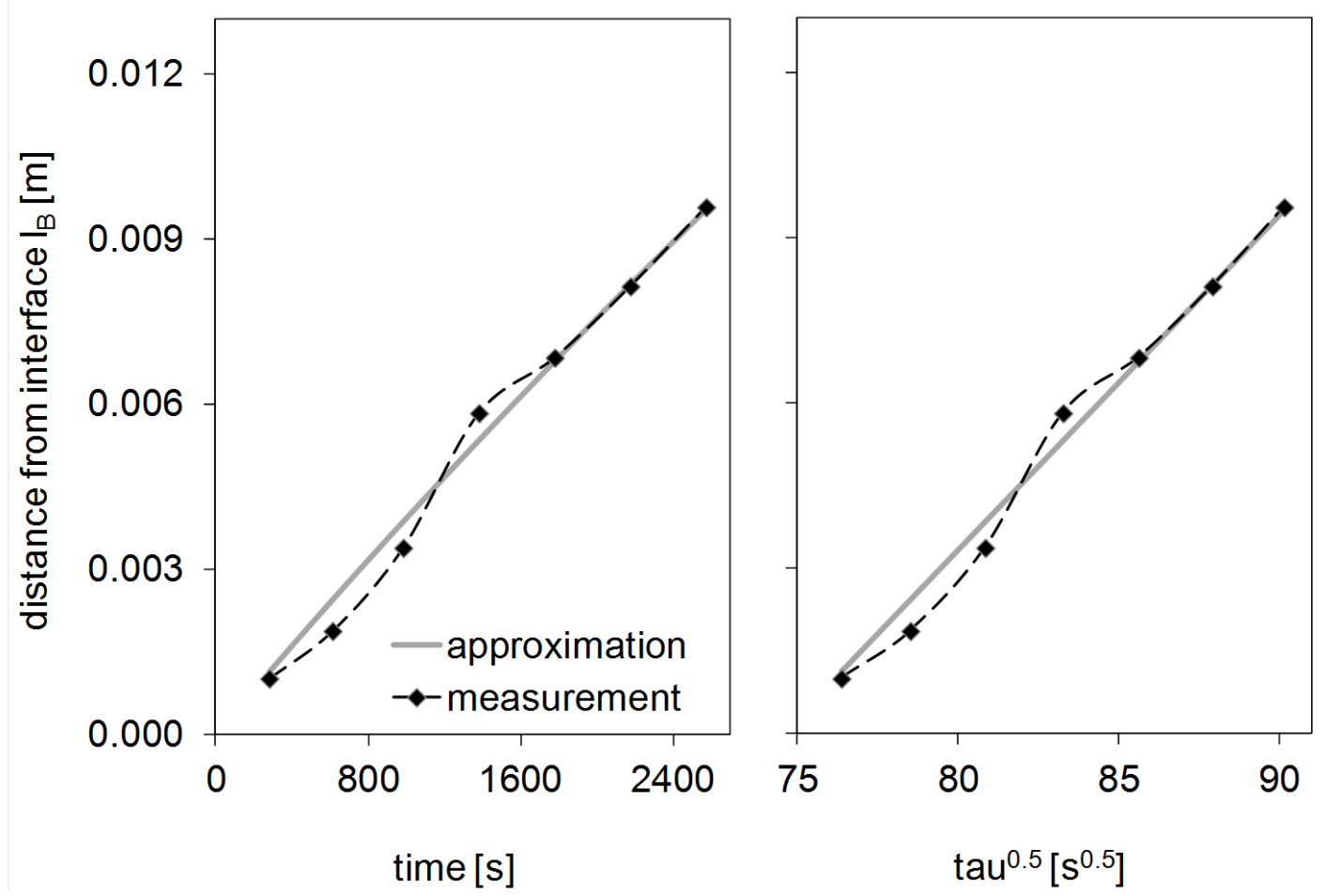

Figure 8

Measured and approximated evolution of the distance between the moisture front and the first brick-mortar interface, as a function of the time elapsed since passing the interface (left) and as a function of the shifted time $\tau$ (right) for the Brocken et al. sample. 